\title{
Effects of the Learning Company Approach on Students' Achievement in Chemistry
}

\author{
Toyin. E. Owoyemi ${ }^{1} \&$ Taiwo. A. Olowofela ${ }^{1}$ \\ ${ }^{1}$ Department of Special Education and Curriculum Studies, Adeyemi College of Education, Ondo, Nigeria \\ Correspondence: Toyin. E. Owoyemi, Department of Special Education and Curriculum Studies, Adeyemi \\ College of Education, Ondo, Nigeria. E-mail: toyinowoyemi2006@yahoo.com
}

Received: September 14, 2012

Accepted: October 4, 2012 Online Published: December 31, 2012

doi:10.5539/ass.v9n1p142

URL: http://dx.doi.org/10.5539/ass.v9n1p142

\begin{abstract}
The study investigated the effects of learning company approach on students' achievement in chemistry. Learning company is a didactically constructed classroom structure, analogous to an 'ideal' company, the learning environment here is used for the simulation of practical, profession-oriented tasks in business, through this model, students are supposed to learn how processes in a company occur. The design of the study was experimental; the sample consisted of 120 randomly selected secondary school students. Two hypotheses and three research questions guided the study. Relevant instruments were used for data collection and data collected were analyzed using t-test and descriptive statistical tools. Results revealed that students taught using the learning company approach performed significantly better than those taught using conventional teaching method. Learning company approach was also found to encourage independent study, cooperation and critical thinking among students. Recommendations were made based on the findings.
\end{abstract}

Keywords: learning company, approach, students' achievement, chemistry

\section{Introduction}

Chemistry as a science subject is a subject rich in theories, many scholars believe that the impressive number of quality and scope of theories, laws and paradigms in chemistry, have enthroned the subject with prestigious position as the queen of science subjects and veritable source of nourishment for the growth and development of many other disciplines (Oriaifo,1991).

Over the years different teaching methods and principles have been used for instruction in the teaching of chemistry in senior secondary school level for students to learn scientific methods, chemical content and to understand the nature of science. The idea of teaching methodology in chemistry include lesson planning, appropriate learning environment, timing, class participation, demonstration, recitation, memorization, as well as the actual lesson delivery. To date, chemistry teaching methods in Nigeria although properly conceived through guided discovery approach leaves much to be desired in terms of implementation, as lesson planning is usually not sufficiently well articulated, space and materials are more often than not inadequate, while lesson delivery is still largely based on abstract exposition and learning done by rote memorization, as a consequence, students' achievement is low, however recent public outcry on falling standard in education and students' performance do not augur well for the future (Oriaifo, 1993).

For effective teaching to take place a good method must be adopted by the teacher, and the teacher has to take into consideration some factors affecting students, like background, level of knowledge assimilation, environment or the learning climate and the learning goals (Bonwell and Eison, 1991). The teacher's decision on any teaching method must be flexible, and he must be willing to adjust style according to students' ability and interest, since students' success in the classroom is largely based on effective teaching method (Johnson and Johnson, 1990). Teachers are aware that students learn in different ways, but almost all students will respond well to praise, students have different ways of absorbing information and demonstration of acquired knowledge in the classroom. Teachers have to use techniques which can cater for multiple learning styles, help students retain information and strengthen understanding. A variety of strategies and methods are being used to ensure that all students have equal learning opportunities (Bershon, 1992).

It is pertinent to know that learning can be done in three ways; visual, kinaesthetic and auditory. According to 
Lieberman (2004), it is necessary to try and include all three as much as possible into any lesson being taught. Higher percentage of learners are familiar with the auditory and visual ways of learning, but the kinesthetic method is an uncommon process of learning which involves collaboration of students to perform a specific task (Lieberman, 2004). The kinaesthetic method is a greater way of learning that allows active participation in the teaching-learning process, students learn best in this way by being able to relate the lesson, since they are physically taking part in some ways, group projects and discussions are great ways to welcome this type of learning.

In an attempt to make chemistry learning effective and interesting for students, several requirements for change in common practice of school chemistry experimentation were incorporated into the teaching system, experiments were made open, participatory and cooperative thereby by leading to a motivating and attractive learning environment, students work together in group performing task, brain-storming, researching, developing and trailing models and presenting their final result for the given experiment (Nakleh, Polles \& Malinal, 2002).

For learning to be more cooperative and collaborative, the learning company approach was introduced to help students succeed in tasks performance. The learning company or learning office approach comes from the field of didactics of business and professional education in Germany (Paetzold \& Lang, 1999) . The learning company is a didactically constructed classroom structure, analogous to existing or 'ideal' companies, the learning environment here is used for the simulation of practical, profession-oriented tasks in business, through this model, students are supposed to learn how process in a company occur. They should recognize how businesses are structured, and how different tasks within the company are related in a cause-effect relationship to one another, to the economy and to the environment.

In learning company students are grouped into companies or departments to work together in order to achieve a specific task. Teachers make sure that students assigned to company contains good mix of skills, students from each team research their own operations, identifying key tasks, and developing a workable time frame. Each team or group plans, models, trials, and develops their part of the operation. The CEO (leader of company or group) ensures they stay in touch with the other groups to meet deadlines. Students record their research and decision making in a portfolio based on a template provided by their teacher.

It might be reasoned that teaching on how businesses and industrial structures function is not one of the main goals of chemistry education in schools, however, the possibility of using the learning company approach for motivation, encouragement of cooperative learning and the training of experimentation in different styles seem to be very promising. Therefore, the present study investigates the effect of learning company approach in the teaching of chemistry.

\subsection{Literature Review}

FME (1985) gives some importance of teaching chemistry at the senior secondary school level in Nigeria as follow:

1) To facilitate a transition in the use of scientific concepts and techniques acquired in integrated science with chemistry.

2) To provide the students with basic knowledge in chemical concepts and principles through efficient selection of content and sequencing.

3) To show chemistry in its inter-relationship with other subjects.

4) To show chemistry and its link with industry, everyday life, benefits and hazards.

5) To provide a course which is complete for pupils who do not intend to proceed to higher education, while it is the same time a reasonable and adequate foundation for a post-secondary school course.

The frame work of chemistry in the science curriculum has been built on the students' acquisition of knowledge and understanding of

1) Scientific phenomena

2) Scientific vocabulary, terminologies and conventions

3) Scientific and mathematics measurement and safety aspects.

4) Scientific and technological applications with their sociological, economics and environmental implications (Adesoji, 2000).

The achievement of students in chemistry curriculum is determined by; 
1) High caliber of cognitive and material students from the junior secondary school level.

2) Availability of academically, competent, professionally sound and enduringly committed teachers.

3) Provision of moderately equipped libraries and laboratory.

4) Reasonable teacher-student ratio and well trained laboratory technologists (Ajala, 2002).

Chemistry education is expected to prepare its recipient for the achievement of life goals. Oriaifo (1991) gave three major dimensions of chemistry as follow;

1) The content or body of knowledge which include facts, principles, law and theories.

2) The processes or the ways and means which the knowledge is acquired.

3) The attitude component that is scientific, attitude, ethics, interest and values.

For a balance teaching and learning of Chemistry, the teaching of the subject must accommodate all of these dimensions for the fulfillment of its educational objectives. Contemporary teaching methods in chemistry emphasize the humanistic approach which in this context is the process approach plus emphasis on chemistry for life with the learner as a significant factor. Basically the process stresses mental skills which provide fundamental structures for learning to learn the subject on a continuous basis, usually beyond preparation for examination or certification. In addition, human aspect of the learner is not neglected. Accordingly, emphasis is placed on adequacy of relationship with students and enthusiasm in working with them.

As an intellectual tool, chemistry is a creation of mind, its laws and generalizations are founded in reality but its interpretations centralization is determined by man's perception, conceptual thought, and inferences which are all functions of man's internal components.

A suitable method for teaching chemistry in senior secondary school must take into consideration the objectives and philosophy of the course, nature of the student, available school facilities and the entire learning climate. Therefore an acceptable teaching style for successful chemistry education should;

1) Emphasize the individuality of the learner, his unique natural, as well as his cognitive and deontological levels of development.

2) Assist the students to gain knowledge and skills in content as well as enhance his understanding, appreciation and interest in nature and natural phenomena.

3) Encourage students' participation in the learning process while teacher relating positively and enthusiastically with the students thereby serving as a guide in the learning process.

4) Should foster initiative, creativity and resourcefulness in the student (FME, 1985).

Students' achievement in chemistry is a function of the proficiency of the teacher and the quality of the supporting provisions such as books, laboratory (its structure and equipment) and motivation (Oriaifo, 1991). This implies that both tangible and non-tangible variables in ensuring students achievement in chemistry education essentially, availability of superior resources (materials and human) must be supported by adequate motivation and interest. Accordingly, chemistry curricula must also include elements of motivation to attract and sustain students' interest in the subject; usually such motivation component is introduced in different forms ranging from cosmetics design of text book cover to stringent selection and organization of learning experiences.

Teachers' effectiveness in chemistry is a factor that must be given consideration, if success in the utilization of texts and desirable students' progress is to be guaranteed. The question of effectiveness of teaching has attracted the attention of scholars in all fields of education. Oriaifo (1991) asserted some teachers' effective qualities that are particularly relevant in this context relate to;

1) Ability to stimulate intellectual imagination.

2) Ability to organize and put across subject matter.

3) Positive, progressive, progressive attitude with pleasing personality

4) Student-oriented disposition; friendly, enthusiastic and unfeigned willingness to help students.

5) Good knowledge of the subject matter and ability to explain in clear terms with illustrations and appropriate examples.

6) Being resourceful, willing and able to improvise teaching and learning materials.

7) Personal confidence and ability to motivate and inspire confidence in learners. 
These qualities and many are more important for the chemistry teacher who constitutes the life wire of the curriculum. Therefore, education authorities recruiting teachers for chemistry education must not lose sight to acknowledge teachers' effectiveness qualities, if the goals of excellence and pragmatism must be achieved.

\subsubsection{Learning Company Approach and Students' Achievement}

A contingency view of any business organization hold that 'the firm' must be responsive to focus developments in its environment otherwise there may be a crack in the organization process. This approach goes well in the teaching of chemistry, especially in practical classes, in chemistry practical we convert observations from experiments into readable concepts and theory while in a company, bricks, equipment and structural form are being converted into living entity to earn a pay. People come and go in companies; they are obviously in their own way learners, because the input of an individual goes a long way in the accomplishment of the given task.

Learning here is performance and company related, it means knowledge and competence will enhance the ability to succeed in various tasks and participatory activity to achieve the task (Witteck, Most, Kienast, and Eilks, 2007). The imperatives oflearning company are focused on how 'management' of the firm can learn to be more adaptive and mobilize the capacity of other employees as individuals and in various groups to learn. In other words, a conclusion can be reached that the learning company approach is the approach which involves the students in the classroom taking up responsibilities and duties as workers or employees in a company to achieve a recognized goal. The need for this approach comes in two folds; personal development flavour about the students, which is an attempt to make students take responsibility for performing better, and to make them active in learning processes

The outcome of this learning projects new behaviors and responses which can be used by the group to become more active, quicker, productive and competitive (Cooper, 1995). Learning company is not sequential, although it starts with strategy and ends with creation of learning opportunities. It is an energetic, normal, persuasive device for those wishing to manage change, it is also a professional "change agent" model-independent of the context of change or analysis of change processes, here, characteristics become prescriptions-commitments to flexibility, self-management, incremental, experiment and participative activities. The learning company approach in the teaching of chemistry enhance student achievement which help them develop and improve their efforts to bring about change in rational, action research and harmonistically gained steps.

We can assume that students working together as a company in a chemistry class can proffer solutions that would aid industrial growth, sustainable organizational development, knowledge productivity, innovation and change across the globe. The approach is an aspect of cooperative learning where students work together to "attain group goals that cannot be obtained by working alone or competitively" (Johnson et.al., 1990). The main purpose of cooperative learning is to actively involve students in the learning process, a level of student empowerment which is not possible in a lecture format. It is a process which requires knowledge to be discovered by students and transformed into concepts which students can relate and this expands knowledge through new learning experiences.

Learning company utilizes the idea of Vygosky, Piaget, and Kohlber, in that both the individual and the social setting are active and dynamic in the learning process, as students attempt to imitate real life learning. By combining team work and individual accountability, students work towards acquiring both knowledge and social skills. Learning company allow students to work together in small groups with individuals of various talents, abilities and backgrounds to accomplish a common goal. Each individual team member is responsible for learning the task and also for helping the other members of the team learn. Students work until each group member successful understands and complete the assignment (Panitz, 1996).

Learning company approach and cooperative learning cannot be separated from each other because both involve students working together to achieve a goals

\subsubsection{The learning Company Basic Components}

Bell Loncella (2004) gives eight basic components of cooperative learning which is also approved in the learning company approach

1) Task: This is the problem expected by each group to solve

2) Individual: Before working as a group or team to solve the problem, each member of the group should estimate an answer. 
3) Cooperative: now as team work together, there must be just one set of answers for the whole group, there should be share for agreement and every team member must be able to explain the strategies used in solving each problem

4) Expected criteria for success: everyone must be able to explain the strategies used to solve each problem.

5) Evaluation: best answer within available resources

6) Individual accountability: one or more group members will be chosen randomly to explain

a) The answer

b) How each problem was solved

7) expected behaviors: active participation, checking, encouraging, and elaborating by all group members

8) Inter-group Cooperation: whenever it is helpful, check procedure, answer and strategies with one another group.

\subsubsection{Learning Company Elements}

Bell-Loncella (2004) gave five basic elements which form the acronym "PIGSface"

1) Positive interdependence: "we are all in this together, either we all sink or swim" company has manual goal joint rewards (company bonus points) shared resources (one page with the assignment) and assigned role.

2) Individual accountability: each student performance is assessed individually

3) Group processing: on task completion, a look at 'how well did we do' an honest assessment makes a winning team.

4) Social skills: this is about leadership, decision making, trust building, communication and conflict management among company members.

5) Face-to-face promotive interaction: by default, learning is being promoted by helping, learning and encouraging each other in the company.

In order to accomplish the company task, each group member must have a role. There are two general categories,

1) Work Roles

2) Group Roles

These are discussed below:

1) Leader / Manager: manages the group and ensures that the company members are fulfilling their rolesand working cooperatively

2) Reader: if only one copy of the task is distributed, then one company member reads the instructions out loud to the rest of the group.

3) Recorder: records group answers and explanation along with other pertinent information. Also, write down the group discussion and edits the group report.

4) Reporter or spokesperson: restates to the group the company's major conclusions effectively. The instructor accepts only the answer given by the reporter or sometimes the recorder.

5) Technician / Calculator: performs all technical operations for the group including use of calculator, computer e.t.c

6) Materials Handler: collects materials for the group (from central position) necessary to accomplish the task.

7) Encourager: ensures that members are all participating

8) Checker: ensures that all members in the group understand and can explicitly explain how to arrive at the answer or conclusion.

9) Accuracy coach: corrects any mistakes in another member's explanation or summary.

10) Skeptic: makes sure that all possibilities have been explored by asking questions like "what other possibilities are there," "let's try to look at this in another way", "I'm not sure me are on the right track".

11) Reflector / observer: observes, reports on the group dynamics and keeps track of how well the group operates.( Bell-Loncella, 2004) 


\subsubsection{Benefits of learning Company Approach over Other Teaching Methods}

Panitz (1996) lists over fifty benefits; these can be summarized into four major categories.

1) social

2) psychological

3) academic

4) assessment

Learning company promotes social interaction, thus students benefit in a number of ways from the social perspective by having students explain their reasoning and conclusion, and it helps develop oral communication skills. Because of the social interaction among students, learning company can be used to model the appropriate social behaviors necessary for employment situations. By following the appropriate structuring for learning company, students are able to develop and practice skills that will be needed to function in society and work place. These skills include; leadership, decision making, communication and conflict-management. The cooperative environment in learning company also develops a social support system for students. Other students, the instructor, administrators, other school staffs, and parents become integral parts of the learning process, thus supplying multiple opportunities for support to the students.

Students also benefit psychologically from cooperative learning atmosphere in the learning company. Johnson et. al. (1993) claim that "cooperative learning experience promotes positive attitudes" towards learning and instruction than another teaching methodologies, because students play an active role in the learning process hence students' satisfaction with the learning experience is enhanced. It also helps to develop interpersonal relationship among students. The opportunity to discuss their ideas and views in smaller groups and receive constructive feedback on those ideas help to build student self-esteem. In a lecture format, individual students are called to respond to a question in front of the entire class without having much time to think, but the learning company creates a safe, maturing environment because solution come from the group rather than from an individual. Errors in conditions and thought process are corrected within the group before they are being presented to the whole class.

Students also tend to be inspired by instructors who take the time to plan activities which promote an encouraging environment (Janke,1980), receiving encouragement in a cooperative setting from both the instructor and team members help to develop higher self-efficiency, as a result of this, student's grade tends to increasethus the provision of academic benefits to students. Research revealed that students taught under cooperative climate learned and retained significantly more information than student taught with other methods. Requiring students to verbalize their ideas to the group helps them to develop more clear concepts, thus the process becomes fully embedded in the students' memory. Vygotsky supports this concept in his research on ego centric speech by claiming that verbalization plays a significant role in task solution (Bershon, 1992). Discussions within the group leads to more frequent summarization because the students are constantly explaining and elaborating, which in turn validates and strengthens thought, students also benefit from learning company academically in the sense that there is more of a potential for success when students work in groups; individuals tend to give when they get stuck, whereas a group of students is more likely to find a way to keep going (Johnson et .al., 1990).

There are also many benefits of learning company from the aspects of assessment; it provides instant feedback to the students and instructor because the effectiveness of each class can be observed. As instructors move around the room and observe each group of students interacting and explaining theories they are able to detect misconceptions early enough to correct them.

In addition to the four major categories of benefits detailed above, schools utilizing this method of learning report on increase in students' attendance because they feel valuable and necessary part of their group. Mcbrienand Brandt (1997) revealed that students are likely to act out in a cooperative setting, students act out to get attention, however the 'stage' is removed in a cooperative environment because it is very difficult to gain the attention of the whole class when students are divided up into smaller groups, as a result class disruptions are reduced because students are allowed to socialize during the learning process.

According to Johnson et. al. (1990), learning in a cooperative atmosphere help to reduce violence, because group consensus is promoted, blame is eliminated, and honour, friendliness and quality virtues are promoted.

Research also shows that learning company also build diversity awareness among students. It encourage students to use their differences to help each other, because students are placed in a situation where they are able to 
interact with peers that they otherwise may never socialize with, behaviors which might appear odd in other settings become understandable when students are given the opportunity to explain and defend their reasoning. In a traditional classroom, there is little opportunity for students to defend their perspective. As students observe each other's reasoning process, there is more room to understand and appreciate their differences (Johnson et. al., 1993).As a result a much deeper understanding of cultural and individual differences is developed (Yager, Johnson and Johnson, 1985).

In addition, because students are placed in a supporting environment where group processing skills are essential, they are more likely to accept these differences than they would in a competitive or a non-interactive environment.

\section{Purpose of the Study}

The purpose of the study is to determine whether learning company approach enhance the academic achievement of students in chemistry.

\section{Statement of the Problem}

The study attempts to investigate if the learning company approach affect performance of students in chemistry

\section{Research Hypotheses}

This study sets to find out if there is difference in the performance of students taught with learning company approach in chemistry, with the aim in mind, the research hypotheses are stated as follows.

1) There is no significant difference in the achievement of chemistry students taught using the learning company and conventional method.

2) There is no significant difference in the achievement of chemistry students using learning company method due to gender.

\section{Research Questions}

1) Does learning company approach motivate and encourage independent work among students?

2) Does learning company approach promotethe spirit of cooperation and team work among students?

3) Does learning company approach promote critical thinking and creativity among students?

\section{Method}

\subsection{Research Design}

Since the purpose of this research is to investigate the effects of learning company approach on the teaching of chemistry in secondary schools, the researcher used an experimental design for the study.

\subsection{Sample and Sampling Techniques}

The sample for the study includes two randomly selected secondary schools from Ondo West Local Government Area of Ondo State. One hundred and twenty (120) students were randomly selected from senior secondary school one (SSS I) of the two schools to form the sample size.

\subsection{Research Instruments}

In order to collect relevant information from the respondents in the study, the researcher made use of three research instruments which include:

Chemistry Achievement Test (CAT)

Learning Company Approach Questionnaire (LCAQ)

Lesson Notes on the topics used in the study

6.3.1 Chemistry Achievement Test (CAT)

The Chemistry achievement test was developed by the researcher and it consists two sections; section A seeks for 
personal bio-data of the students such as name, sex, class, school name, age, etc. Section B consists of twentyitem questions on the topics on separation techniques used in the study.

\subsubsection{Learning Company Approach Questionnaire (LCAQ)}

The questionnaire was adopted from Witteck et.al, 2006. It also consists of two sections, section A seeks for the bio-data of the students and section B consists twelve items to identify the interest/attitude of students in learning company approach group.

\subsubsection{Lesson Plan}

Two different set of lesson plans were prepared for the study, one for learning company and the other for the conventional teaching method, the lesson notes covered some topics on separation techniques which include; filtration, evaporation to dryness, magnetic separation, and extraction method.

Lesson Plan for Learning Company Approach (LPLA)

The LPLA was adaptedfromWitteck, et.al. (2007). The lesson plan consists of seven steps:

1) In the Learning Company experimental group, students are divided into small groups. Each group is composed of 10students, and each group is expected to choose a speaker, materials collectors, time manager, minute taker and public relations person.

2) The students receive their tasks as a group.

3) Students were given 15 munites of preparation time for the experiments. This time is spent on discussion with their teacher in advance of starting the hands-on activity. Manual containing instructions for the task at hand and the list of chemicals and equipment available was given to each group. Also, textbooks and relevant working materials were provided to the students.

4) After discussing and planning the procedures, the students must carry out their experimental work and carefully document all activities.

5) The presentation should be carefully made orally with illustration the chalk board, so that students in the other groups can absorb and understand the contents and the experimental results presented.

6) The students' experimental results are presented to the whole class at the very end by the speaker of each group. Students receive a worksheet, with which they must document the results of the other group.

7) In the final stage after the presentation, the students can strengthen their knowledge of the various procedures from the other groups. They can ask questions on those procedures which they either did not understand or need clarifications, or question on the end results.

Lesson Plan for Convectional Method Group

This was done by following the normal way of preparing lesson note for chalk and talk method and researcher presents the lesson orally to the students with some illustrations on the chalkboard.

\subsubsection{Validation and Reliability of the Research Instruments}

The draft of the research instruments were submitted to the supervisor and also to three experts in chemistry for moderation. This is an attempt to validate the research instrument for both face and content validity; their comments and suggestions were considered in the final draft of the three instruments.

As regards the reliability of the instruments, Kuder Richardson formula 20 was used to test for the reliability of CAT, and the reliability coefficient of 0.76 was obtained. Croubach alpha was used for testing the reliability of LCAQ and 0.68 was obtained.

\section{Procedure for Data Collection}

The researcher asked for the permission of the principals of the concerned schools to carry out the research work. Students were divided into groups to perform tasks on separation techniques. There were five groups performing different tasks which include: filtration, magnetic separation, extraction, evaporation to dryness and there was another filtration group performing a task different from the first filtration group.

Group and task work include: 
Group 1: Removal of apple juice from apple fruit.

Group 2:Removal of magnetic materials with the use of magnet from a mixture of iron filling and saw dust.

Group 3: Removal of fat from potato chips

Group 4:Removal of salt from a salt solution.

Group 5:Removal of chalk particles from chalk suspension.

The achievement test was given to students after the activities to know the effects of learning company teaching approach. Then for the traditional teaching methods, students were taught through the conventional method and the achievement test was also administered after the teaching -.learning process. The test items were completed and was collected back immediately for the analysis of the stated hypotheses.

\section{Data Analysis}

The data collected were analysed using T-test statistical tool to test the formulated hypotheses while the research questions raised in the study were answered using frequency count and simple percentage.

\subsection{Results}

Hypothesis 1: there is no significant difference in the achievement of students taught chemistry using the learning company approach and the conventional teaching method.

Table 1. T-test analysis of the students' achievement in chemistry using the two methods

\begin{tabular}{lllllll}
\hline VARIABLE & $\mathrm{N}$ & MEAN & S.D & DF & T.CAL & T.CRIT \\
\hline Learning company approach group & 50 & 9.94 & 2.83 & 118 & 7.82 & 1.96 \\
Conventional method group & 70 & 8.26 & 2.26 & & & \\
\hline
\end{tabular}

At 0.05 alpha level

As shown in table 1, the t-calculated value of $7.82>t$ - critical value of 1.96 . Therefore, the null hypothesis 1 is rejected and the alternative hypothesis is accepted. This implies that there is significant difference in the achievement of student taught chemistry using the learning company approach and students taught chemistry using the conventional teaching method.

Hypothesis 2: there is no significant difference in the achievement of students taught chemistry using the learning company approach due to gender.

Table 2. T-test analysis of effect of gender on the students' achievement in chemistry using the learning company approach

\begin{tabular}{lllllll}
\hline VARIABLE & $\mathrm{N}$ & MEAN & S.D & DF & T-CAL & T-CRIT \\
\hline Male group & 24 & 10.58 & 2.73 & 48 & 2.19 & 1.96 \\
Female group & 26 & 9.25 & 2.77 & & & \\
\hline
\end{tabular}

At 0.05 alpha level

As shown in table 2, the t-calculated value of $2.19>\mathrm{t}$-critical value of 1.96 therefore, the null hypothesis 2 is rejected and the alternative hypothesis is accepted, this implies that there is significant difference in the achievement of male and female students taught chemistry using the learning company approach.

Research question 1: Does learning company approach motivates and encourages independent work among students?

Table 3. Influence of learning company approach on students' motivation and independent study

\begin{tabular}{llllll}
\hline S/N & ITEM & AGREE & $\%$ & DISAGREE & $\%$ \\
\hline 1 & $\begin{array}{l}\text { I worked much more independently in the learning company than I } \\
\text { normally do during our lessons. }\end{array}$ & 45 & 05 & 10 \\
2 & $\begin{array}{l}\text { I missed the direct control of my work by the teacher after each step } \\
3\end{array}$ & 16 & 32 & 34 & 68 \\
$\begin{array}{l}\text { I worked much more intensely in the learning company than I } \\
\text { normally do during our lesson }\end{array}$ & 44 & 88 & 06 & 12 \\
4 & $\begin{array}{l}\text { I prefer it if the teacher discussed all topics with the whole class than } \\
\text { to work in small groups }\end{array}$ & 13 & 26 & 37 & 74 \\
5 & I think that I learned a lot in the learning company & 47 & 94 & 03 & 06 \\
\hline
\end{tabular}


From table 3,90\% of the students agreed that they worked more independently in the learning company than they do during other classes. While only $10 \%$ disagreed with the statement. It was also revealed that $68 \%$ of students in learning company did not miss the direct control of their work after each step while $32 \%$ agreed with the statement. The response on the third question shared that $88 \%$ students worked more intensely in learning company while $12 \%$ disagreed with the statement. It was also revealed that $74 \%$ of students in learning company disagreed that teacher discuss all topics than to work in groups while $26 \%$ agreed with the statement. It was revealed that $94 \%$ of students agreed that they learned a lot in the learning company while $6 \%$ disagreed with the statement

Research Question 2: does learning company approach promotes the spirit of cooperation and team work among students?

Table 4. Influence of learning company on cooperation and team work attitude of students

\begin{tabular}{llllll}
\hline S/N & ITEM & AGREE & $\%$ & DISAGREE & $\%$ \\
\hline 1 & $\begin{array}{l}\text { I don't like the learning company because my works too dependent on } \\
\text { my classmates }\end{array}$ & 12 & 24 & 38 & 76 \\
2 & $\begin{array}{l}\text { I found the learning company confusing and lacking in structure } \\
3\end{array}$ & 07 & 14 & 43 & 86 \\
$\quad \begin{array}{l}\text { I like the learning company because I could work out something with } \\
\text { the other students }\end{array}$ & 47 & 94 & 03 & 06 \\
4 & It was difficult to organize the learning company by ourselves & 23 & 46 & 27 & 54 \\
\hline
\end{tabular}

From table $4,76 \%$ of students disagreed that they don't like the learning company because their work is too dependent on their classmates, while $24 \%$ agreed with the statement. It was also revealed that $86 \%$ of students disagreed that they found learning company confusing and lacking on structure. It was also revealed that $94 \%$ of students agreed that they like learning company because they could work out something with other students while $6 \%$ disagreed with the statement. It was also revealed that $54 \%$ of students disagreed that learning company was difficult to organize while $46 \%$ agreed with the statement.

Research question 3: does learning company approach encouraging critical thinking and creativity among students?

Table 5. Influence of learning company approach in promoting critical thinking and creativity

\begin{tabular}{llllll}
\hline S/N & ITEM & AGREE & $\%$ & DISAGREE & $\%$ \\
\hline 1 & $\begin{array}{l}\text { I like the learning company because we could carry out our } \\
\text { experimentindependently in our group }\end{array}$ & 96 & 02 & 04 \\
2 & $\begin{array}{l}\text { I like the learning company because we were allowed to carry out } \\
\text { experiments with a given recipe }\end{array}$ & 86 & 07 & 14 \\
3 & $\begin{array}{l}\text { Using different teaching methods makes our lessons more fun and } \\
\text { less boring. }\end{array}$ & 81 & 09 & 18 \\
\hline
\end{tabular}

Table 5 reveals that $96 \%$ of students in learning company agreed to like learning company because they could out their experiments independently in their group while $4 \%$ of the students disagreed with the statement. It was also revealed that $86 \%$ of students agreed to like learning company because they were allowed to carry out experiments with a given recipe while $14 \%$ of students disagreed with the statement. It also showed that $82 \%$ of the students agreed that using different teaching methods makes lesson more fun and less boring while $18 \%$ of the students disagreed.

\subsection{Discussion on the Results}

It was revealed from table 4.1 that there is significant difference in the achievement of students taught with learning company approach and the conventional teaching method. This implies that learning company improves students' understanding of a subject by using a structured approach which involves a series of steps, requiring students to create, analyze and apply concepts and as a result, they frame new concepts by basing their conclusions on prior knowledge, and this process results in a deeper understanding of the material and more potential to retain the material compared to other students taught with the conventional teaching method. It can be deduced that teaching students with the learning company enables students to acquire not only scientific knowledge but also science process skills. Chemistry teachers should use learning company approach which exposes students to participating scientific activities rather than the conventional teaching method which 
encourages only role memorization of scientific knowledge. The use of this kind of approach has been found to result in higher cognitive achievement, better development of high-level thinking skills, increased student self-confidence and satisfaction and better attitudes towards subject matter (Copper, 1995; Lazarowitz \& Hertz-Lazarowitz, 1998; Doymus, 2008). The findings also corroborate the submission of Witteck and Eilks (2006) that, younger students can also use this approach to learn effectively in chemistry.

As shown in table 2, there is significant difference in the achievement of students taught chemistry using the learning company approach in respect to their gender. It was observed that male students performed better than female students. It was revealed that both male and female students in the learning company did not perform at the same pace which implies that gender of students has influence on the achievement of students in the learning company approach.In the social relation of adolescents, girls keep to themselves, but boys at this stage want to show off their ego so as to impress their female counterpart especially in learning company roles. The general saying that 'what a man can do a woman can do better' is not always correct, but an assumption can be made, that the achievement of students upon gender in the learning of chemistry is determined by the learning climate, girls may perform better than boys in the conventional teaching method while boys on the other hand may perform better than girls in the learning company when it comes to activity roles.

Table 3 shows the responses of students on the influence of learning company approach on students' motivation and independent study. The responses from the questionnaire revealed that higher percentage of the students agreed that they worked very intensely and learned a lot in the learning company, this is in line with the findings of Witteck et.al (2006). The responses described students as showing very high motivation, lively,successful activity, and learning a great deal. The findings also corroborates that of Wood (2006), who observed that this kind of learning provides a more positive attitude towards science learning and better problem solving skills.

Cooperative attitude to teamwork was revealed among students in table 4. It was shown that higher percentage of students liked learning company approach and found out that it was not confusing nor lacking in structure because they were able to work with other students and it was not too difficult organizing themselves. The positive consideration from the students was based on the cooperative learning atmosphere and highly self-directed activity which gave chance to develop a good learning climate during task performance (Witteck et.al, 2006).

From table 5, it was observed that most students showed interest towards learning company because they could carry out their experiments independently in their group with a given recipe which makes its more fun and less boring for the students. Students really enjoyed the learning company because they were more active, and allowed to think and act more freely than they do in normal classes. Learning here, helps students develop skills necessary to work on projects too difficult and complex for any one person to do in a reasonable given amount of time.

\section{Conclusion}

The findings of this study showed that the use of learning company approach for teaching chemistry concepts enables students to acquire science process skills. This also makes it possible for them to work in team which creates an environment where students can promote each other's success and support team effort which is not possible in the conventional teaching method. The conventional teaching method in chemistry merely encourages students to memorize scientific concepts and principles which they regurgitate during examinations. The findings of this study have projected the learning company approach to science teachers and students as an approach that provides a more positive attitude towards chemistry learning and better problem skills. The approach also gives room for development of high level of student motivation and development of non-cognitive skills such as team work ability.

\section{Recommendations}

Based on the findings from this study, it is recommended that learning company approach should be incorporated as one of the methods for teaching chemistry in secondary schools;

1) Government should provide conducive learning environment by providing adequately equipped chemistry classrooms as well as properly equipped chemistry laboratories to enhance the acquisition of science process skills in learning company.

2) Government should utilize the services of academic bodies like science teachers association of Nigeria (STAN), all Nigerian conference of principles of secondary schools (ANCOPSS) national union of teachers (NUT): and faculties of education in the universities to organize in-services training programmes, workshops, conference and seminars for serving chemistry teachers to updates their knowledge on the importance of learning 
company approach in the teaching of chemistry.

3) There is need for overall renovation of chemistry curriculum at all levels which will support the use of teaching company approach to aid new and emerging technologies.

4) There should be increase in funding of science subjects in Nigeria so as to help the implementation of the learning company approach.

5) Experts in chemistry education should identify areas that are yet to be developed in experimental chemistry so that the learning company approach can be introduced.

6) More research work should still be done on the influence of gender on achievement of students in chemistry, so as to reach a conclusion as to whether male students are more intelligent than female students

\section{References}

Adesoji, F. A. (2000). Rethinking the Science Curriculum. University Press, Ibadan, Nigeria.

Ajala, A. (2002). Designing Content of the Curriculum. Maybest Publications, Ibadan, Nigeria.

Bell-Loncella. (2004). A Few Worlds About Cooperative Learning in Chemistry. University of Piltsburgh, Johnstown

Bershon, B. L. (1992). Cooperative Problems Saving. In Hertz Lazarowitz (Ed.), Interaction in Cooperative Learning (pp. 36-38). Cambridge Press New York.

Bonwell, C. C., \& Eison, J. A. (1991). Active, Learning, Creating Excitement in the Classroom. Higher Education report 1. George Washing University, School of Educational human development, Washington, D.C.

Cooper, M. M. (1995). Cooperative Learning: An Approach for Large Enrollment Courses. Journal of Chemical Education, 72, 162-164. http://dx.doi.org/10.1021/ed072p162

Doymus, K. (2003). Teaching Chemical Equilibrium with the Jigsaw Technique. Research in Science Education, 38, 249-260. http://dx.doi.org/10.1007/s11165-007-9047-8

Eilks, I., \& Ralle, B. (2002). Participating Action Research within Channel Education. Chemistry Education Research and Practices, 87-98.

Federal Ministry of Education. (1985). National Curriculum for Senior Secondary school. FME Journal, 3, $75-102$.

Janke, R. (1980). Computational Errors of Mentally Retarded Students. Psychology in the School, 17, 30-32. http://dx.doi.org/10.1002/1520-6807(198001)17:1<30::AID-PITS2310170106>3.0.CO;2-9

Johnson, D. W., \& Johnson, R. T. (1990). Social Skills for Successful Group Work. Educational Leadership Journal, 47(4), 29-33.

Lazarowitz, R., \& Hertz-Lazarowitz, R. (1998). Cooperative Learning in the Science Curriculum. In B. J. Fraser, \& K. G. Tobin (Eds.), International Handbook of Science Education (pp. 623-640). Dordrecht: Kluwer. http://dx.doi.org/10.1007/978-94-011-4940-2_26

Lieberman, A. (2004). Teachers' Leadership. Jossey-Bass Printers California.

McBrien, J. L., \& Brandt, R. S. (1997). The Language of Learning: A Guide to Education Terms. Alexandria Press New York.

Nakleh, M., Polles, S. T., \& Malina, K. (2002). Learning Chemistry in a Laboratory Environment. Journal of Chemical education, 8, 69-94.

Oriafo, S. O. (1991). In-service Education for Teachers a Challenge of Effectiveness. Sam Bookman Publisher, Ibadan Nigeria.

Oriafo, S. O. (1993). Curriculum Developmentin Nigeria. Sam Bookman Publisher, Ibadan, Nigeria.

Paetzold, G., \& Lang, M. (1999). The Learning; Consensus and Controversy. Educational Leadership Journal, 47(4), $52-54$.

Panitz, T. (1996). A Definition of Collaboration Vs. Cooperative Learning. Retrieved June 18, 2011, from http://www.Igu.ac.uk/Deliberations/CollaboLearning/Panitz.html

Wilteck, T., Most, B., Kienast, S., \& Eilks, I. (2007). A Lesson Plan on 'Methods of Separating Matter' Based on the Learning Company Approach. Chemistry Education Research and Practice, 8(2), 108-119. 
http://dx.doi.org/10.1039/b6rp90024k

Witteck, T., \& Eilks, I. (2006). Max Sour Ltd. -Open Experimentation and Problem Solving in Cooperative Learning Company. School Science Review, 88, 95-102.

Wood, C. (2006). The Development of Creative Problem Solving in Chemistry. Chemistry Education Research and Practice, 7, 96-113. http://dx.doi.org/10.1039/b6rp90003h

Yager, S., Johnson, D. W., \& Johnson, R. (1985). Oral Discussion Group to Individual Transfer and Achievement in Cooperative Learning Groups. Journal of Traditional Psychology, 77(1), 60-66. 